\title{
Autorenverzeichnis Band 6,1996/Author Index Vol. 6,1996
}

\section{Verhaltenstherapie}

Aigner, M. 114

Bachmann,K.M. 4201 Binter, G. 114 Brodbeck,J. 4201 Buchkremer, G. 14

Lotz, C. 3143

Lupke,U. 122

Margraf,J. 3135 Moggi,F. 4201 Münchau, N. 3143 

de Jong-Meyer, R. 3124 Demal,U. 114 Donati, R. 4201

Eher, R. 114 Ehlert,U. 122 ElFalaky,A. 3135 Engberding, M. 3124

Fabisch,H. 294

Fabisch, K. 294

Fichter, M. 143

Foltys, M.J. 3162

Gerber,W.D. 4210 
Petermann, F. 276

Renner,W. 133 Rief,W. 143 Rodde, S. 3135 Rossel, E. 2107

Schaible,R. 3143 Schneider, S. 3135 Schoenen, J. 4210 Schuster, P. 4222 Serim,M. 114 Siniatchkin,M.S. 4 210 Straube, E.R. 2 88 Süss-Burghart, H. 2 100, 4234 

Hand, I. 3143 Hansel, B. 288 Hellhammer, D. 122 Hellmeister, G 288 Heuser,J. 143 Hirsbrunner, H.-P 4201 Kirn, T. 3124 Kropp, P. 4210 
Trabert, W. 3162

Warschburger, P. 276 Weiss, A. 3143 Wiedemann, G. 14 Wittchen, H.-U. 3 170, 4222 Wittig, R. 4201 Wolfradt,U. 288 Wunderlich, U. 14 

Langs, G 294 Leibetseder, M. 133 Lenz, G. 114

ZapotoczkyH.G 294 Zarbock,G 4244

274 